\title{
Origin and Molecular Specification of Globus Pallidus Neurons
}

\author{
Sandrina Nóbrega-Pereira, ${ }^{1,2 *}$ Diego Gelman, ${ }^{1 \star}$ Giorgia Bartolini, ${ }^{1}$ Ramón Pla, ${ }^{1}$ Alessandra Pierani, ${ }^{3}$ and $0 s c a r$ Marín ${ }^{1}$ \\ ${ }^{1}$ Instituto de Neurociencias, Consejo Superior de Investigaciones Científicas y Universidad Miguel Hernández, Sant Joan d'Alacant 03550, Spain, ${ }^{2}$ Doctoral \\ Program in Experimental Biology and Biomedicine, Center for Neuroscience and Cell Biology, University of Coimbra, 3004-517 Coimbra, Portugal, and \\ ${ }^{3}$ Institut Jacques-Monod, Centre National de la Recherche Scientifique, Unité Mixte de Recherche 7592, Université Paris Diderot, 75205 Paris, France
}

The mechanisms controlling the assembly of brain nuclei are poorly understood. In the forebrain, it is typically assumed that the formation of nuclei follows a similar sequence of events that in the cortex. In this structure, projection neurons are generated sequentially from common progenitor cells and migrate radially to reach their final destination, whereas interneurons are generated remotely and arrive to the cortex through tangential migration. Using the globus pallidus as a model to study the formation of forebrain nuclei, we found that the development of this basal ganglia structure involves the generation of several distinct classes of projection neurons from relatively distant progenitor pools, which then assemble together through tangential migration. Our results thus suggest that tangential migration in the forebrain is not limited to interneurons, as previously thought, but also involves projection neurons and reveal that the assembly of forebrain nuclei is more complex than previously anticipated.

\section{Introduction}

The vertebrate CNS is organized in two main types of anatomical and functional units, named brain nuclei and laminated structures. These two types of building blocks use different histological arrangements to group neurons with specific patterns of connections and therefore play a fundamental role in organizing neural circuitries in the brain. Development of brain nuclei and laminar structures requires the coordination of two major histogenetic processes, neurogenesis and neuronal migration, which, respectively, account for the generation of different neuronal classes and their subsequent allocation in the CNS. Over the past decades, we have learned a great deal about the mechanisms controlling these processes during the formation of laminar structures, most notably through the analysis of the cerebral cortex (Gupta et al., 2002; Rakic, 2007). In contrast, our knowledge on the mechanisms that generate

Received Aug. 17, 2009; revised Jan. 8, 2010; accepted Jan. 11, 2010.

This work was supported by Spanish Ministry of Science and Innovation Grant SAF2008-00770, CONSOLIDER Grant CSD2007-00023, a European Young Investigator scheme award (www.esf.org/euryi) (0.M.), and the European Commission through STREP contract number 005139 (INTERDEVO) (0.M., A.P.). S.N.-P. was supported by Foundation for Science and Technology Predoctoral Fellowship POCI 2010/FSE and the Doctoral Program in Experimental Biology and Biomedicine (Coimbra, Portugal). D.G. was recipient of a Marie Curie International incoming fellowship. A.P. is a Centre National de la Recherche Scientifique Investigator. We thank M. Bonete, T. Gil, and M. Pérez for excellent technical assistance, S. McKnight (Npas1) and T. Jessell (Er81) for antibodies, and S. A. Anderson (Nkx2-1-Cre) and K. Campbell (D/x5/6-Cre-IRES-Gfp) for mouse strains. We also thank the Institut Clinique de la Souris (IIlkirch, France) and the Consortium National de Recherche en Genomique for the production of the Pax6-Cre mouse line. We are grateful to members from the Borrell, Marín, and Rico laboratories for stimulating discussions and comments on previous versions of this manuscript.

*S.N.-P. and D.G. contributed equally to this work.

Correspondence should be addressed to Dr. Oscar Marín, Instituto de Neurociencias de Alicante, Consejo Superio de Investigaciones Científicas y Universidad Miguel Hernández, Sant Joan d’Alacant 03550, Spain. E-mail: o.marin@umh.es.

S. Nóbrega-Pereira's present address: Spanish National Cancer Research Center, Melchor Fernandez Almagro 3, Madrid 28029, Spain.

D01:10.1523/JNEUROSCI.4023-09.2010

Copyright $\odot 2010$ the authors $\quad 0270-6474 / 10 / 302824-11 \$ 15.00 / 0$ discrete brain nuclei, with the appropriate size, location, and neuronal composition, is still very limited.

The generation of neuronal diversity in the cerebral cortex is mainly achieved by the sequential production of cell types in a defined order. Thus, cortical progenitors go through a series of changes in intrinsic properties that control their competence to make different classes of projection neurons with very diverse connectivity (Molyneaux et al., 2007; Leone et al., 2008). This process is coordinated with the translocation of newborn cells by radial migration, in which cortical neurons use the long processes of radial glial cells as a "guiding cable" that they follow to migrate to their final position (Rakic, 1972; Rakic et al., 1974; Nadarajah and Parnavelas, 2002; Noctor et al., 2004). Neuronal diversity in the cerebral cortex also increases with the incorporation of interneurons born at remote locations and that reach the cortex through tangential migration (Corbin et al., 2001; Marín and Rubenstein, 2001; Wonders and Anderson, 2006).

It has long been assumed that the formation of nuclei in the forebrain involves a similar sequence of events than in the cerebral cortex, although the resulting neuronal assembly has a very different organization. Development of the striatum, for example, is thought to involve three sequential steps: (1) production of different classes of projection neurons from the same common progenitor pool in the lateral ganglionic eminence (LGE); (2) radial migration of striatal projection neurons to form a distinct neuronal assemble in the telencephalic mantle; and (3) tangential migration of interneurons from a remote progenitor pool in the medial ganglionic eminence (MGE), which further increases cell diversity within the nucleus (Deacon et al., 1994; Olsson et al., 1995, 1998; Marín et al., 2000; Wichterle et al., 2001; Hamasaki et al., 2003). A similar process has been proposed recently for the generation of some nuclei in the amygdala (Hirata et al., 2009). 


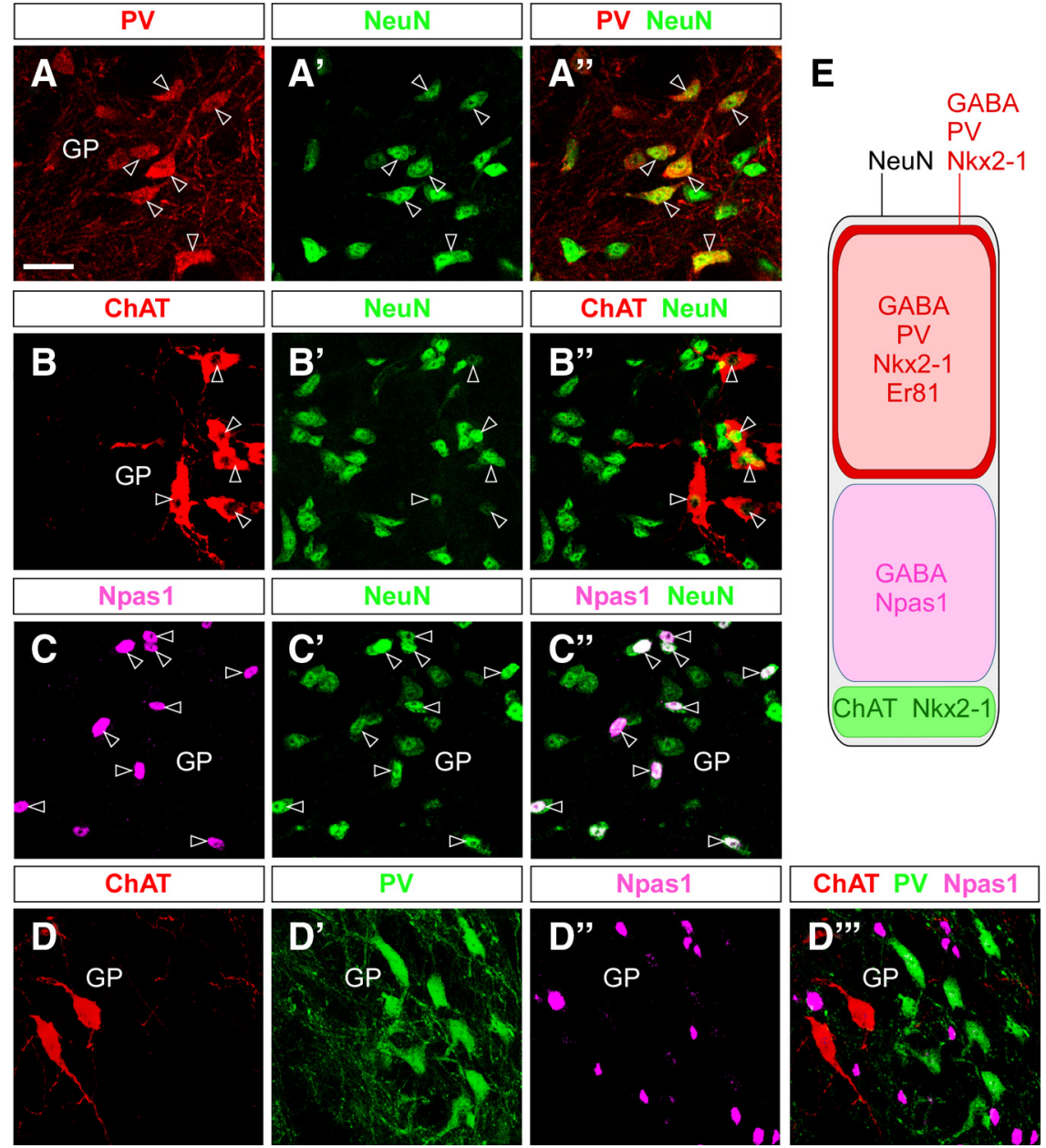

Figure 1. Neuronal populations in the globus pallidus. $\boldsymbol{A}-\boldsymbol{D}^{\prime \prime \prime}$, Coronal sections through the telencephalon of $\mathrm{P} 60$ wild-type mice showing coexpression of PV $\left(\boldsymbol{A}, \boldsymbol{A}^{\prime \prime}, \boldsymbol{D}^{\prime}, \boldsymbol{D}^{\prime \prime \prime}\right)$, ChAT $\left(\boldsymbol{B}, \boldsymbol{B}^{\prime \prime}, \boldsymbol{D}, \boldsymbol{D}^{\prime \prime \prime}\right)$, Npas1 $\left(\boldsymbol{C}, \boldsymbol{C}^{\prime \prime}, \boldsymbol{D}^{\prime \prime}, \boldsymbol{D}^{\prime \prime \prime}\right)$, and the neuronal marker NeuN $\left(\boldsymbol{A}^{\prime}, \boldsymbol{A}^{\prime \prime}, \boldsymbol{B}^{\prime}, \boldsymbol{B}^{\prime \prime}, \boldsymbol{C}^{\prime}, \boldsymbol{C}^{\prime \prime}\right)$ in the GP. Open arrowheads point to examples of double-labeled cells. Note that PV, ChAT, and Npas1 are expressed by primarily nonoverlapping populations of neurons in the GP.E, Schematic representation of the three distinct neuronal populations present in the GP and the molecular markers used to identify them. Scale bar, $50 \mu \mathrm{m}$.

To determine whether brain nuclei in the forebrain are formed following the general principles outlined above, we investigated the development of another basal forebrain structure, the globus pallidus (GP). This important node basal ganglia nucleus contains several distinct classes of projection neurons but few interneurons (Kita, 1994; Kita and Kitai, 1994; Nambu and Llinás, 1994, 1997; Bevan et al., 1998; Cooper and Stanford, 2000; Kita and Kita, 2001; Kita, 2007). Thus, the GP represents an ideal model to understand the origin of projection neuron diversity and their relationship to the different modes of migration during the assembly of nuclear structures. Our results indicate that the assembly of the GP involves at least five different progenitor lineages from three distinct embryonic domains.

\section{Materials and Methods}

Mouse lines. Wild-type and green fluorescent protein (GFP)-expressing transgenic mice (Hadjantonakis et al., 2002) were maintained in a CD1 background. Nkx2-1-Cre (Xu et al., 2008), Dbx1-Cre (Bielle et al., 2005), Rosa-EYFP (Srinivas et al., 2001), and Pax6-Cre transgenic mice were maintained in a mixed C57BL/6 $\times 129 / \mathrm{SvJ} \times \mathrm{CBA}$ background. The bacterial artificial chromosome (BAC) used to generate Pax6-Cre mice spanned $\sim 181 \mathrm{~kb}$ of genomic DNA around the Pax6 locus and was purchased from BacPac Resources Center (supplemental Fig. S1, available at www.jneurosci.org as supplemental material). The codon-improved Cre re- combinase with a nuclear localization signal was fused to the translation initiation codon using an approach based on the PCR and followed by an simian virus 40 polyadenylation signal. The line was produced by pronuclei microinjection at the Institut Clinique de la Souris (Illkirch, France). The day of vaginal plug was considered as embryonic day 0.5 (E0.5). Animals were kept at the Instituto de Neurociencias, and experiments were performed following Spanish and European Union regulations.

In utero electroporation. Timed-pregnant Nkx2-1-Cre or wild-type females were deeply anesthetized, and the abdominal cavity was cut open. Embryos were exposed in the uterus, and $1 \mu \mathrm{l}$ of a $1 \mu \mathrm{g} / \mu \mathrm{l}$ solution of $p C A G G S-L o x P-$ STOP-LoxP-EGFP [MGE and preoptic area (POA) electroporations] or $p C A G G S-E G F P$ or pCAGGS-RFP (LGE electroporations) plasmids were injected into the lateral ventricle of the telencephalon through the uterine wall. Square electric pulses of $35 \mathrm{~V}$ and $50 \mathrm{~ms}$ were passed through the uterus five times, spaced $950 \mathrm{~ms}$ apart, using a square pulse electroporator (CUY21E; Nepa GENE). DNA was specifically directed toward the subpallium, as described previously (Borrell et al., 2005).

In utero transplantation. In utero ultrasoundguided transplantation of MGE-derived cells was performed as described previously (Pla et al., 2006). For each experiment, the MGE from $8-10$ E12.5 GFP-expressing mice were dissected under a stereomicroscope. Explants were washed in 0.5 $\mathrm{ml}$ of L-15 medium (Invitrogen) containing DNase I $(100 \mu \mathrm{g} / \mathrm{ml})$, and cells were mechanically dissociated by repeated pipetting. Dissociated cells were pelleted by centrifugation ( $5 \mathrm{~min}, 1000$ $\mathrm{rpm})$, resuspended in $6 \mu \mathrm{l}$ of L-15 medium with DNase I, and kept on ice until injection. All donor pregnant females were injected with bromodeoxyuridine (BrdU) $(50 \mathrm{mg} / \mathrm{kg}) 12 \mathrm{~h}$ before dissection. High-density cell suspensions $(25,000$ cells $/ \mu \mathrm{l}$ ) were front loaded into beveled glass micropipettes (50 $\mu \mathrm{m}$ diameter) prefilled with mineral oil and mounted in a pressure microinjector (VisualSonics). Recipient pregnant females at E12.5 were anesthetized with sodium pentobarbital $(0.625 \mathrm{mg} / 10 \mathrm{~g}$, i.p. $)$, and their uterine horns were exposed and mounted under an ultrasound microscope (VisualSonics). The tip of the micropipette was inserted into the MGE under real-time ultrasound guidance, and 100-150 $\mathrm{nl}$ of cell suspension was injected.

In situ hybridization and immunohistochemistry. For in situ hybridization, embryonic brains were fixed overnight in 4\% paraformaldehyde (PFA) and embedded in Tissue-Tek OCT compound (Sakura Finetek Europe). Twenty micrometer frozen coronal and horizontal sections were hybridized with digoxigenin-labeled probes against Er81 (Lin et al. 1998), as described previously (Flames et al., 2007). For immunohistochemistry, embryonic brains were fixed in $4 \%$ PFA at $4^{\circ} \mathrm{C}$ from $2-6 \mathrm{~h}$. Brains were then embedded and cut frozen at $20 \mu \mathrm{m}$ in the cryostat or sectioned in the vibratome at $60 \mu \mathrm{m}$. Postnatal mice were anesthetized with an overdose of sodium pentobarbital and transcardially perfused with $4 \%$ PFA. Postnatal brains were removed, fixed for $1-3 \mathrm{~h}$ at $4^{\circ} \mathrm{C}$, and cryoprotected in $30 \%$ sucrose in PBS. Brains were then cut frozen on a sliding microtome at $40 \mu \mathrm{m}$. The following primary antibodies were used: rat anti-BrdU (1:100; Accurate Chemical and Scientific), goat anticholine acetyltransferase (ChAT) (1:100; Millipore Bioscience Research Reagents), rabbit anti-Er81 (1:5000; a gift from T. Jessell, Columbia University, New York, NY), rabbit anti-GABA (1:1000; Sigma), chicken antiGFP (1:3000; Aves Labs), rabbit anti-Nkx2-1 (1:2000; Biopat), rabbit 
anti-Npas1 (1:1000; a gift from S. McKnight, University of Texas Southwestern, Dallas, TX), mouse anti-neuronal nuclei (NeuN) (1: 500; Millipore Bioscience Research Reagents), rabbit anti-parvalbumin (PV) (1:5000; Swant), and mouse anti-PV (1:5000; Swant). The following secondary antibodies were used: goat anti-chicken 488, donkey anti-rabbit 555, donkey anti-mouse 555 (all from Invitrogen), and donkey anti-rat cyanine 3 (Jackson ImmunoResearch). The immunofluorescence detection of enhanced yellow fluorescent protein (EYFP) was performed using an anti-GFP antibody. $4^{\prime}, 6^{\prime}$ Diamidino-2-phenylindole (Sigma) was used for fluorescent nuclear counterstaining. GP neurons were mapped and quantified using a microscope equipped with Neurolucida software.

Quantification. For the birthdating of GP neurons, $\mathrm{CD} 1$ wild-type pregnant females were injected with BrdU $(50 \mathrm{mg} / \mathrm{kg})$ at E10.5, E11.5, E12.5, and E13.5. PV/BrdU and Npas1/BrdU double-labeled cells were counted using images obtained in a confocal microscope from three different rostrocaudal levels of the GP from three different animals per stage. For the quantification of colocalization patterns, labeled cells were counted from three different sections throughout the rostrocaudal extent of the GP from three different animals per stage. In all cases, data were expressed as average \pm SEM

\section{Results}

Molecular profiling of globus pallidus neurons

Previous studies have shown that the GP mostly consists of GABAergic projection neurons, some of which express the calcium binding protein PV (Fig. $1 A-A^{\prime \prime}$ ) (Kita and Kita, 2001). In addition, the GP contains some cholinergic neurons (ChAT) (Fig. $\left.1 B-B^{\prime \prime}\right)$, although they do not seem to constitute a major component of this structure. Instead, these cholinergic neurons represent an extension of the basal magnocellular complex that intercalates through the medial aspect of the caudoputamen nucleus and the GP (Kita, 2007). As part of a large effort to delineate distinct molecular profiles in the mouse subpallium, we found that the adult GP also contains many cells that express Npas1 (Fig. 1C), a basic helixloop-helix/PAS domain transcription factor that is expressed by many GABAergic neurons in the forebrain (Zhou et al., 1997; Cobos et al., 2006). We observed that virtually all Npas1expressing cells in the GP are neurons, as identified with antibodies against the neuronal marker NeuN (Fig. $1 C-C^{\prime \prime}$ ). Analysis of the relative contribution of these populations to the neuronal complement of the GP suggests that they may represent nonoverlapping groups (PV, $44 \pm 6 \%$; ChAT, $9 \pm 1 \%$; Npas 1 , $33 \pm 5 \%$; averages \pm SEM; $n=3)$. Indeed, triple immunohistochemical analysis revealed that PV-, ChAT-, and Npas1expressing neurons constitute three distinct neuronal populations in this region (Fig. $1 D, E$ ). Because virtually all neurons in the GP are either GABAergic or cholinergic (data not shown), these experiments also indirectly indicated that Npas1expressing neurons in the GP are GABAergic. $50 \mu \mathrm{m}$.
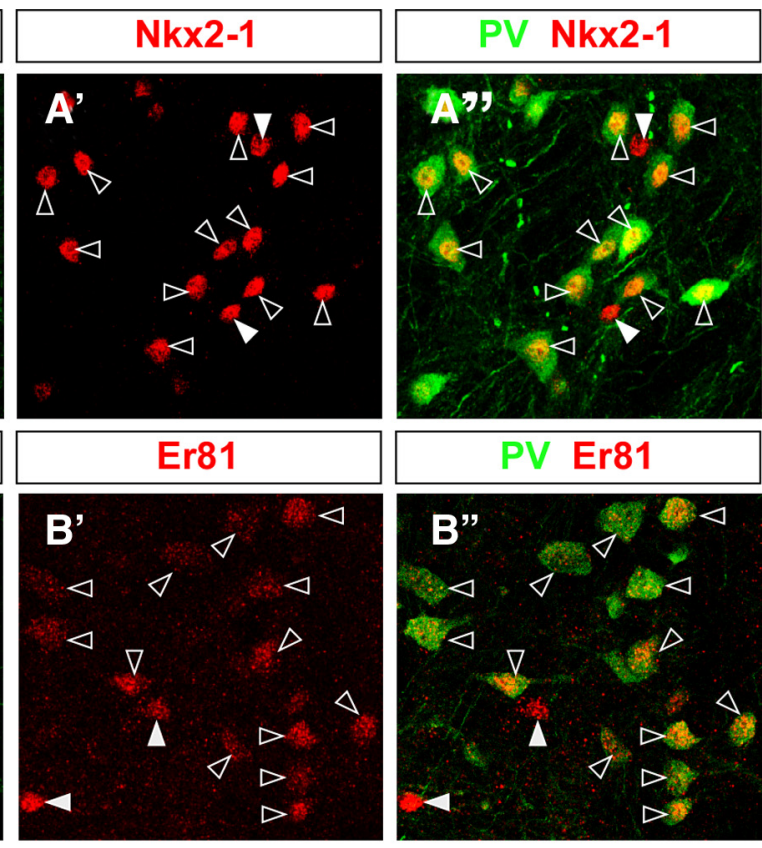

Figure 2. Molecular profile and time of neurogenesis distinguish the two main classes of GABAergic neurons in the globus pallidus. $\boldsymbol{A}-\boldsymbol{B}^{\prime \prime}$, Coronal sections through the telencephalon of $\mathrm{P} 60$ wild-type mice showing coexpression of PV ( $\boldsymbol{A}$ filled arrowheads point to neurons that express only one of the markers. $C$, Quantification of the percentage of PVxpas1-expressing GP neurons labeled with BrdU at different developmental stages. Histograms (Npas1);E12.5, $6.13 \pm 1.61 \%$ (PV), $28.72 \pm 3.00 \%$ (Npas1); E13.5, $1.59 \pm 0.29 \%$ (PV), $6.65 \pm 0.86 \%$ (Npas1). Scale bar

We analyzed the expression of other transcription factors in the adult GP. We have shown previously that Nkx2-1 is expressed in virtually all progenitor cells in the MGE and the POA, as well as in postmitotic cells that populate the GP and other subpallial structures (Sussel et al., 1999; Marín et al., 2000; Flames et al., 2007; Nóbrega-Pereira et al., 2008). Analysis of the expression of Nkx2-1 in the adult GP revealed that virtually all PV-positive $\left(\mathrm{PV}^{+}\right)$neurons also contain this transcription factor (Fig. $2 \mathrm{~A}-$ $\left.A^{\prime \prime}\right)$. Moreover, most $\mathrm{PV}^{+}$neurons were found to also express the ETS transcription factor Er81 $(88 \pm 6 \% ; n=2)$ (Fig. $\left.2 B-B^{\prime \prime}\right)$. Because $\mathrm{PV}^{+}$and $\mathrm{ChAT}^{+}$neurons in the GP accounted for most Nkx2-1-expressing neurons in this structure (data not shown), these experiments also suggested that pallidal Npas1-expressing neurons do not contain Nkx2-1. In summary, our analysis suggested that the mouse GP contains two major populations of GABAergic neurons: Nkx2-1/PV/Er81 neurons and Npas1 neurons (Fig. $1 E$ ).

We next investigated the timing of generation for the two populations of GABAergic neurons present in the GP. To this end, we performed BrdU birthdating at four embryonic days, 

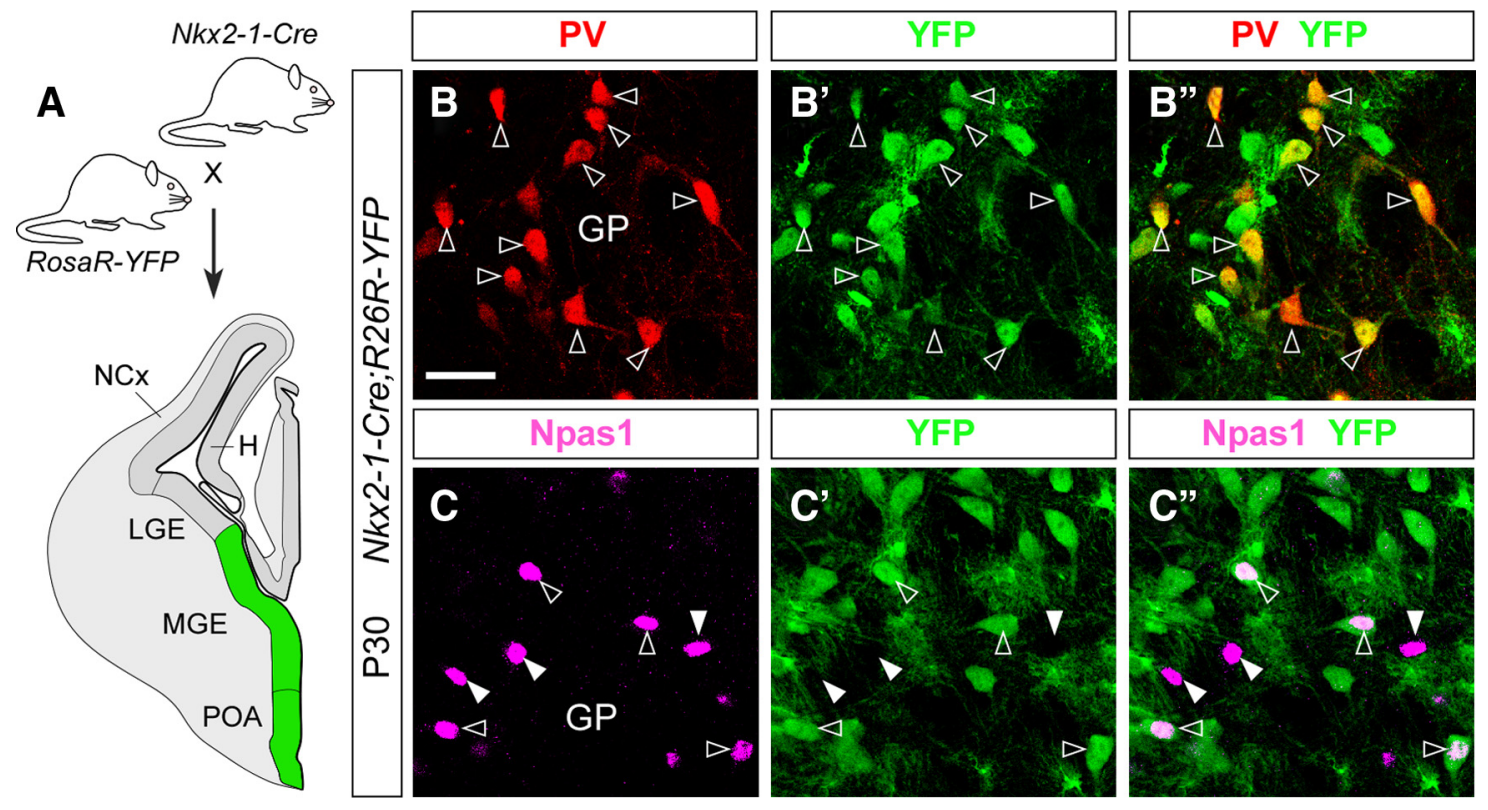

Figure 3. Fate-mapping analysis of the globus pallidus with Nkx2-1-Cre mice. $A$, Schematic of the experimental design, indicating the progenitor domain labeled in Nkx2-1-Cre mice. $B-C^{\prime \prime}$, Coronal sections through the telencephalon of P30 Nkx2-1-Cre; Rosa26R-YFP mice showing coexpression of PV $\left(\boldsymbol{B}, \boldsymbol{B}^{\prime \prime}\right)$ and Npas1 $\left(\boldsymbol{C}, \boldsymbol{C}^{\prime \prime}\right)$ with YFP $\left(\boldsymbol{B}^{\prime}, \boldsymbol{B}^{\prime \prime}, \boldsymbol{C}^{\prime}, \boldsymbol{C}^{\prime \prime}\right)$ in the GP. Open arrowheads point to examples of double-labeled cells, whereas filled arrowheads point to neurons that express only one of the markers. H, Hippocampus; NCx, neocortex. Scale bar, $50 \mu \mathrm{m}$.

E10.5, E11.5, E12.5, and E13.5 and analyzed the distribution of labeled cells at postnatal day 14 (P14). Consistent with previous results in rats (Marchand and Lajoie, 1986), our results indicated that most GP neurons are generated at approximately E11.5 (Fig. 2C). We observed, however, important differences in the time of generation of the two main classes of GABAergic neurons in the GP. Thus, although most $\mathrm{PV}^{+}$neurons were produced between E10.5 and E11.5, neurons expressing Npas 1 were generated through a protracted period of time, with a peak at approximately E12 (Fig. 2C). These results suggest that the dynamics of neurogenesis for GP neurons is more complex that previously recognized.

\section{Nkx2-1-Cre fate mapping reveals multiple origins for globus pallidus neurons}

A recent fate-mapping study using a transgenic mouse line in which the gene encoding for Cre recombinase is expressed under the control of the $N k \times 2-1$ gene $(N k x 2-1-C r e)$ revealed that many $\mathrm{PV}$-expressing neurons in the GP derive from Nkx2-1-expressing cells (Xu et al., 2008). To extend this study, we quantified the relative contribution of $\mathrm{Nkx} 2-1$ cells to the GABAergic neuronal complement in the GP (Fig. 3A). Analysis of Nkx2-1-Cre; Rosa26R-YFP mice at $\mathrm{P} 30$ revealed that virtually all PVexpressing neurons in the GP derive from Nkx2-1-expressing cells $(99.1 \% \pm 0.7 \% ; n=3)$ (Fig. $\left.3 B-B^{\prime \prime}\right)$. In contrast, only approximately half of the Npas1-expressing cells located in the GP seem to derive from an Nkx2-1-expressing territory (47.2 \pm $2.3 \% ; n=3$ ) (Fig. $3 C-C^{\prime \prime}$ ). These results suggest that many Npas1-expressing neurons arise from the MGE and/or POA, but they downregulate the expression of Nkx2-1 during embryonic stages. To test this idea, we analyzed the postmitotic expression of Nkx2-1 in the GP of Nkx2-1-Cre;Rosa26R--YFP mice at different embryonic stages. We found that a small percentage of Nkx2-1derived cells in the GP do not express Nkx2-1 already at E13.5 ( $5 \pm 1 \% ; n=2$; data not shown), and this number increases at later embryonic stages ( $9 \pm 2 \%$ at E15.5; $n=3$; data not shown). These results are consistent with the idea that Nkx2-1-derived,
Npas1-expressing neurons in the GP downregulate the expression of Nkx2-1 as they mature. In summary, our results suggested that all PV-expressing neurons and approximately half of the Npas1-expressing GABAergic neurons in the GP derive from the MGE and/or the POA (Nkx2-1-expressing territories), whereas the remaining Npas1-expressing neurons originate from other regions.

\section{The caudoventral region of the MGE is the origin of many globus pallidus neurons}

To get more insight into the origin of GABAergic neurons in the $\mathrm{GP}$, we next examined the development of those that derive from Nkx2-1-expressing territories. We failed to detect Npas1 expression in the basal ganglia during embryonic stages (data not shown), and so we could not monitor the migration of these cells from their place of origin. Similarly, GP neurons do not express detectable levels of PV until postnatal stages (Mitrofanis, 1992). In contrast, we found that probes against Er81 label a population of cells emanating from the boundary between the caudal MGE and the POA during mid-embryonic stages, and many of these cells seem to invade the prospective territory for the developing GP (Fig. $4 A, B$ ). Because this transcription factor appears to be a reliable marker for PV-expressing neurons in the GP (Fig. $2 B-$ $\left.B^{\prime \prime}\right)$, this observation suggested that GABAergic GP Nkx2-1/PV/ Er81-expressing neurons might derive from the caudoventral MGE (pMGE5 progenitor domain, as defined by Flames et al., 2007). To directly test this hypothesis, we performed a series of in utero electroporation experiments in which we targeted small domains of the MGE at E12.5, a stage in which a considerable proportion of GP neurons are generated (see Fig. 2C). To limit the electroporation target region to the $N k \times 2-1$-expressing territories, we used a plasmid in which expression of Gfp was dependent on Cre-mediated recombination and used this vector to target the ventral telencephalon of E12.5 Nkx2-1-Cre transgenic mouse embryos (Fig. 4C). Analysis of mouse embryos at E15.5 revealed important differences depending on the electroporated region. We observed very few GFP-expressing cells in the GP 

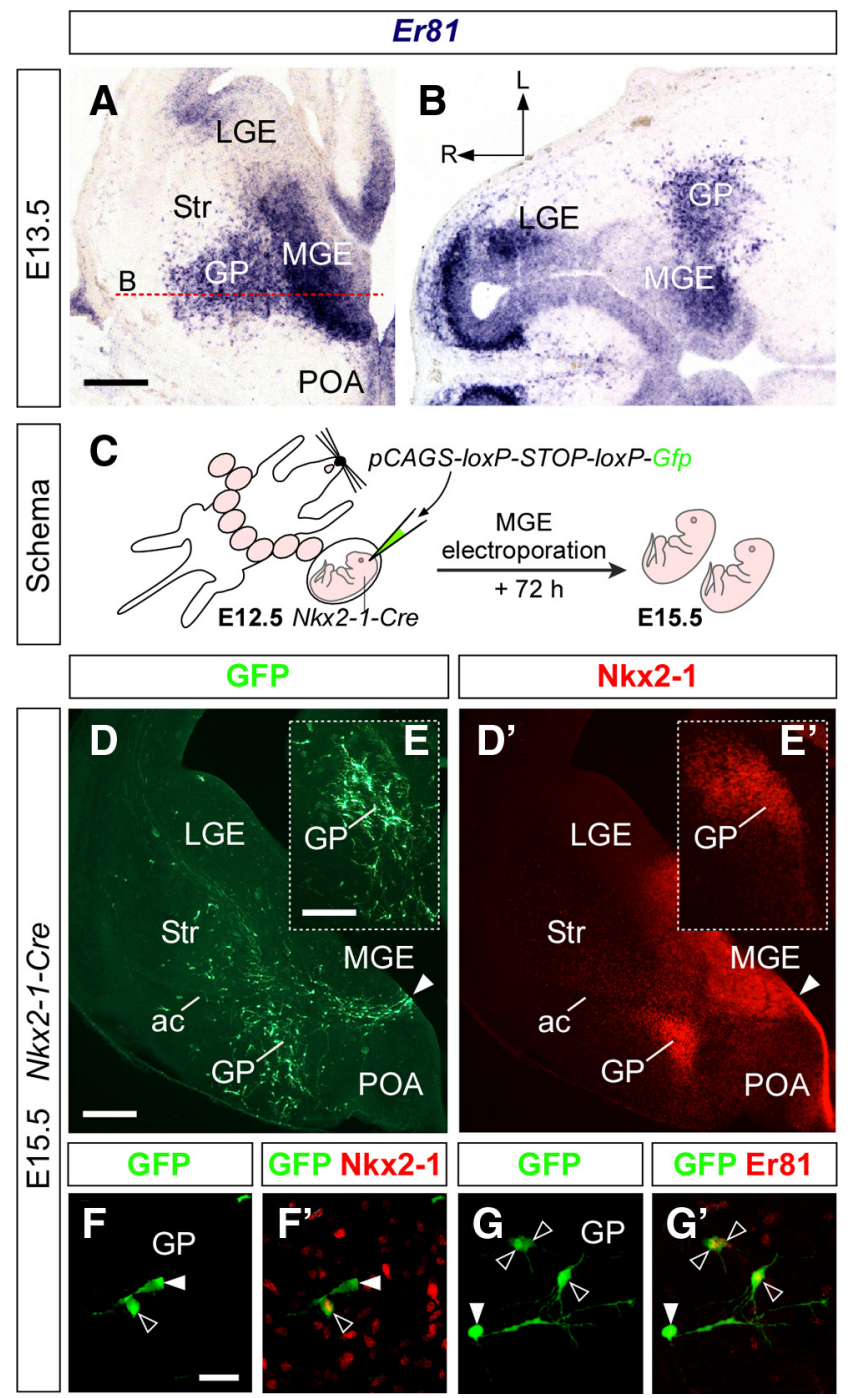

Figure 4. The MGE gives rise to cells that migrate to the embryonic globus pallidus. $\boldsymbol{A}, \boldsymbol{B}$, Coronal $(\boldsymbol{A})$ and horizontal $(\boldsymbol{B})$ sections through the telencephalon of E13.5 wild-type embryos showing the expression of $E r 81 \mathrm{mRNA}$. The red dotted line in $A$ indicates the plane of the section shown in $\boldsymbol{B}$. The arrows indicate lateral $(\mathrm{L})$ and rostral $(\mathrm{R})$ orientations within the brain. $\boldsymbol{C}$ Schematic of the experimental design. $\boldsymbol{D}-\boldsymbol{E}^{\prime}$, A representative case of the distribution of GFPexpressing $(\boldsymbol{D}, \boldsymbol{E})$ and Nkx2-1-expressing $\left(\boldsymbol{D}^{\prime}, \boldsymbol{E}^{\prime}\right)$ cells in a coronal section through the telencephalon of an E15.5 embryo in which the caudoventral MGE was electroporated at E12.5. The white arrowhead in $\boldsymbol{D}$ and $\boldsymbol{D}^{\prime}$ indicates the place of electroporation. Note the presence of many $\mathrm{GFP}^{+}$cells in the ventral division of the GP (known as the ventral pallidum). $\boldsymbol{E}$ and $\boldsymbol{E}^{\prime}$ are high-magnification images of the GP, in a section caudal to that shown in $\boldsymbol{D}$ and $\boldsymbol{D}^{\prime}$ where this nucleus reaches its maximum area. $\boldsymbol{F}-\boldsymbol{G}^{\prime}$, Images of representative cells found in the GP after electroporation in the caudoventral MGE. These cells typically stain for $\mathrm{Nkx2-1}$ ( $\boldsymbol{F}^{\prime}$, open arrowheads) and Er81 ( $\boldsymbol{G}^{\prime}$, open arrowheads). However, some cells do not stain for either of the two markers (filled arrowheads). ac, Anterior commissure; Str, striatum. Scale bars: $\boldsymbol{A}, 200 \mu \mathrm{m} ; \boldsymbol{D}$, $D^{\prime}, 250 \mu \mathrm{m} ; \boldsymbol{E}, \boldsymbol{E}^{\prime}, 100 \mu \mathrm{m} ; \boldsymbol{F}-\boldsymbol{G}^{\prime}, 25 \mu \mathrm{m}$.

when intermediate and rostral levels of the MGE were specifically targeted ( $n=4$; data not shown). In contrast, targeting caudoventral regions of the MGE at E12.5 resulted in the accumulation of many GFP-expressing cells in the GP at E15.5 ( $n=3$ of 5 embryos) (Fig. $4 D, D^{\prime}, E, E^{\prime}$ ). Double immunohistochemistry revealed that, although most $\mathrm{GFP}^{+}$cells found in the GP also expressed Nkx2-1 and Er81, some cells did not (Fig. $4 F, F^{\prime}, G, G^{\prime}$ ). This suggests that the caudoventral MGE is a potential source for both populations of GABAergic GP neurons.
The MGE generates $\mathrm{PV}^{+}$and Npas ${ }^{+}$globus pallidus neurons

The previous experiments suggested that many neurons in the GP derive from the caudoventral aspect of the MGE. Because these experiments were analyzed at E15.5 to verify the electroporation sites and because many of the markers used to profile these cells are only expressed postmitotically, we could not characterized in detail this population of GP neurons. To this aim, we next performed long-term in vivo fate-mapping analysis of the MGE using in utero ultrasound-guided microtransplantation. In brief, we homotypically and isochronically transplanted E12.5 GFPexpressing cells from this region into wild-type host embryos and analyzed the molecular profile of neurons found in the GP of P14 transplanted mice (Fig. 5A). Transplanted MGE-derived cells populating the GP were found to express PV or Npas1 in similar proportions (Fig. $5 B, C$ ), suggesting that the MGE contributes to both populations of GABAergic cells in the GP. To ensure that MGE transplants did not include cells born in other regions that migrated through the MGE at the time of dissection, donor pregnant females were $\mathrm{BrdU}$ injected $12 \mathrm{~h}$ before dissection to identify transplanted cells that divided last in the donor environment. In these experiments, the relative contribution of GFP-expressing MGE-derived cells labeled with BrdU and PV or Npas1 was again similar (Fig. 5D), reinforcing the notion that the MGE contributes to both populations of GP cells. Finally, analysis of in utero ultrasound-guided microtransplantation experiments in which small fragments of the MGE were used as donor tissue (Flames et al., 2007) confirmed that GP neurons preferentially derive from ventral regions of the MGE (data not shown).

\section{The POA generates globus pallidus neurons}

The previous results indicated that GP cells are generated in the MGE. However, because Nkx2-1 is also expressed by POA progenitors, it is possible that this region may also contribute to the neuronal complement of the GP. To begin to test this hypothesis, we performed a series of in utero electroporation experiments in which we specifically targeted the POA at E12.5 and analyzed the distribution of migrating neurons at E15.5 (Fig. 6A). We consistently found a few GFP-expressing cells in the GP in experiments in which the POA was targeted ( $n=4$ of 4 embryos) (Fig. $6 B-C^{\prime}$ ). Double immunohistochemistry revealed that these cells also express $\mathrm{Nkx2}-1$ (Fig. $6 D-D^{\prime \prime}$ ).

To extend these observations, we next performed fatemapping studies using Dbxl-Cre mice (Bielle et al., 2005). In the developing telencephalon, some progenitor cells within the POA and its rostral extension in the septum (Bielle et al., 2005; Flames et al., 2007) express the transcription factor Dbxl. $D b x 1$ is also expressed in the ventral pallium, but previous studies have shown that this region exclusively produces glutamatergic neurons (Bielle et al., 2005; Hirata et al., 2009). Thus, Dbx1-Cre mice seem useful to trace the contribution of $\mathrm{POA} / \mathrm{septal}$ progenitors to GABAergic neurons in the GP (Fig. 6E). Analysis of Dbx1-Cre; Rosa26R-YFP mice at P30 revealed that a small fraction of PVexpressing neurons in the GP derive from $D b x 1$-expressing progenitors $(6.7 \pm 0.5 \% ; n=3)$ (Fig. $\left.6 F-F^{\prime \prime}\right)$. We also found that Dbx1-expressing progenitors gives rise to a small population of Npas ${ }^{+}$neurons in the GP $(2 \pm 0.2 \% ; n=3)$ (Fig. $\left.6 G-G^{\prime}\right)$. These results demonstrated that the POA contributes to both $\mathrm{PV}^{+}$and $\mathrm{Npas}^{+}{ }^{+}$neuronal populations in the GP.

\section{The LGE gives rise to Npas ${ }^{+}$globus pallidus neurons}

We next sought to determine the origin of $\mathrm{Npas}^{+}{ }^{+}$neurons in the $\mathrm{GP}$ that do not derive from Nkx2-1-expressing territories. Anal- 
A
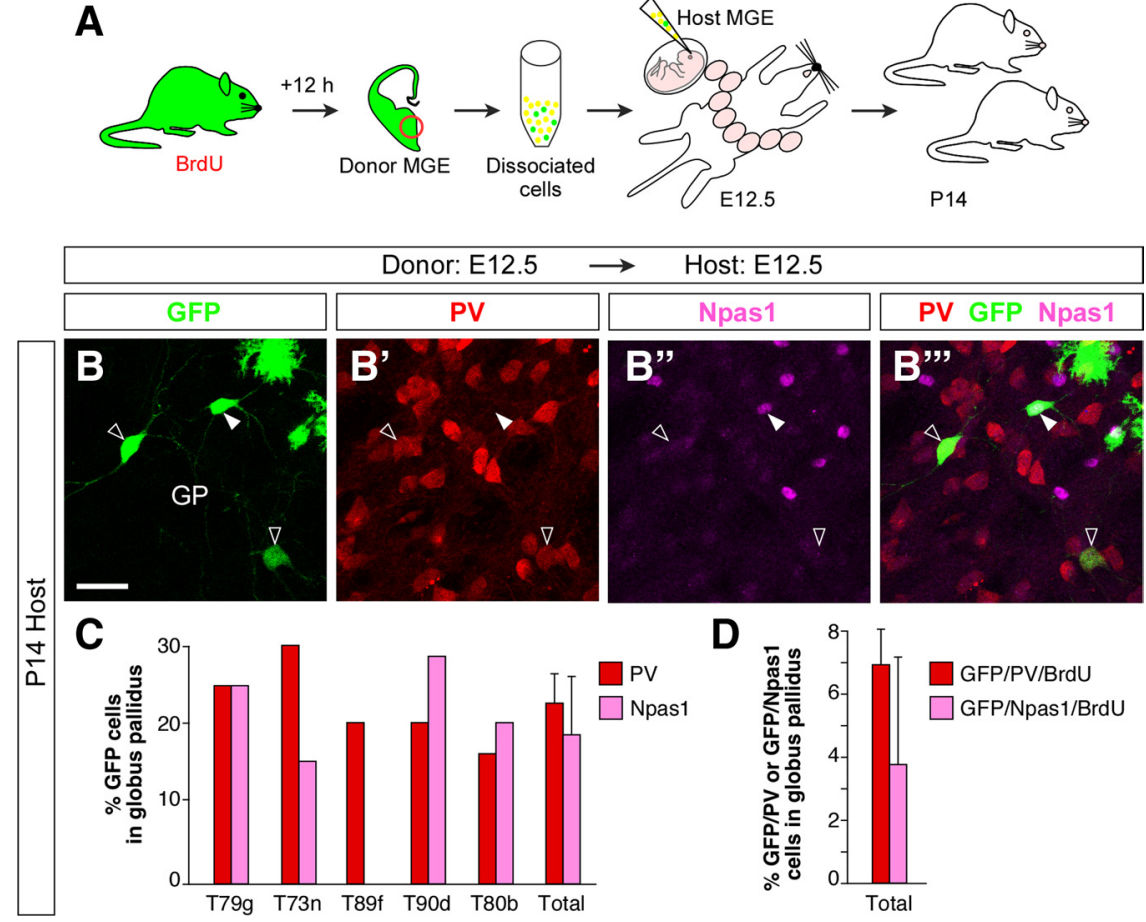

Figure 5. The MGE is the origin of globus pallidus neurons. $A$, Schematic of the experimental design. GFP ${ }^{+}$donor pregnant mice received a single injection of BrdU at E12.5. Twelve hours after BrdU injection, the MGE was dissected from embryos and dissociated. Donor MGE cells were then injected into the MGE of E12.5 host embryos, and host embryos were analyzed at P14. $\boldsymbol{B}-\boldsymbol{B}^{\prime \prime \prime}$, Coronal section through the GP of a transplanted P14 mouse showing the expression of PV $\left(\boldsymbol{B}^{\prime}, \boldsymbol{B}^{\prime \prime \prime}\right)$ and Npas1 $\left(\boldsymbol{B}^{\prime \prime}, \boldsymbol{B}^{\prime \prime \prime}\right)$ in $\mathrm{GFP}^{+}$neurons derived from the MGE $\left(\boldsymbol{B}, \boldsymbol{B}^{\prime \prime \prime}\right)$. Open arrowheads and filled arrowheads indicate PV/GFP and Npas1/GFP doublelabeled cells, respectively. C, Quantification of the percentage of $\mathrm{GFP}^{+}$transplanted neurons expressing PV or Npas1 from five different experiments (T79g, T73n, T89f, T90d, T80b). Histograms show average \pm SEM. T79g, 25.00 (PV), 25.00 (Npas1); T73n 30.77 (PV), 15.38 (Npas1); T89f, 20.00 (PV); T90d, 20.51 (PV), 28.21 (Npas1); T80b, 16.00 (PV), 20.00 (Npas1); total, $22.46 \pm 4.34$ (PV), $17.72 \pm 8.02$ (Npas1). D, Quantification of the percentage of GFP ${ }^{+}$transplanted neurons expressing PV/BrdU or Npas1/BrdU in all experiments. Histograms show average \pm SEM. Total: PV, $6.97 \pm 1.15 \%$; Npas1, $3.76 \pm 3.56 \%$. Scale bar, $50 \mu \mathrm{m}$.

ysis of the expression of Npas1 in Dlx5/6-Cre-IRES-Gfp mice (Stenman et al., 2003), in which most subpallial GABAergic cells are labeled with GFP, revealed that virtually all Npas $1^{+}$neurons in the GP derived from Dlx5/6-expressing cells (data not shown). These results are consistent with the hypothesis that all Npas $1^{+}$ neurons in the GP derive from the subpallium and suggest that the LGE might also contribute to this pallidal structure. To explore this possibility, we performed in utero electroporation experiments in which we targeted the LGE at E12.5 and analyzed the distribution of migrating neurons at E15.5 (Fig. 7A). Of note, in many of our experiments, we also labeled progenitor cells in the ventral pallium, although it is unlikely that pallial cells from this region give rise to GABAergic cells (Chapouton et al., 1999; Stoykova et al., 2000; Toresson et al., 2000). We found a few GFPexpressing cells in the GP in several experiments in which the LGE was targeted ( $n=3$ of 4 embryos) (Fig. $7 B-C^{\prime}$ ). Double immunohistochemistry revealed that these cells do not express Nkx2-1 (Fig. $7 D, D^{\prime}$ ).

To confirm these observations, we performed fate-mapping experiments. To this end, we made BAC transgenic mice expressing the recombinase Cre under the promoter region of the Pax6 gene (supplemental Fig. S1, available at www.jneurosci.org as supplemental material). In the absence of LGE-specific genes, we chose this transcription factor to fate-mapping LGE derivatives because Pax6 transcripts are expressed in LGE progenitor cells during embryonic development (Sussel et al., 1999). Pax6 is also strongly expressed by progenitor cells throughout the pallium but, because pallial cells do not seem to generate GABAergic cells for the subpallium (Chapouton et al., 1999; Stoykova et al., 2000; Toresson et al., 2000), we relied on these mice to study the contribution of the LGE to GABAergic cells in the GP (Fig. 7E).

Analysis of Pax6-Cre;Rosa26R-YFP embryos revealed mosaic GFP expression throughout the LGE and pallium (supplemental Fig. S2, available at www.jneurosci.org as supplemental material), indicative of a relatively low level of recombination (estimated at $\sim 20-25 \%$ ) that was nevertheless confined within the expected domains of Pax6 expression. Analysis of these mice at $\mathrm{P} 30$ revealed that none of the $\mathrm{PV}^{+}$neurons in the GP stained with antibodies against GFP $(n=3)$ (Fig. $\left.7 F-F^{\prime \prime}\right)$. In contrast, many Npas1-expressing cells in the GP were found to derive from Pax6expressing progenitors $(23 \pm 3 \% ; n=3)$ (Fig. $7 G-G^{\prime \prime}$ ).

Despite the mosaic recombination found in Pax6-Cre mice, which likely underestimated our observations, the previous results suggested that the GP Npas1-expressing cells that do not derive from the MGE or POA most likely derive from the LGE. If this were the case, we hypothesized that LGE-derived GP neurons should still be present in Nkx2-1 mutant mice, in which a complete deletion of the GP was reported previously (Sussel et al., 1999). As described previously (Sussel et al., 1999), Nkx2-1-derived neurons were absent from the GP of Nkx2-1 mutant embryos. This included cells expressing Lhx6 or Er81 (Fig. $8 \mathrm{~A}, \mathrm{C}$ and data not shown). In contrast, $\mathrm{Npas}^{+}{ }^{+}$neurons were very abundant in a small structure located just medial to the developing striatum of $N k \times 2-1$ mutants, which resembled an atrophic GP (Fig. $8 B, D$ ). Indeed, we found that the density of Npas $1^{+}$neurons in the mutant GP doubled that found in controls $\left(n=3\right.$; control, $94.8 \pm 7.4$ cells $/ \mathrm{mm}^{2} ; N k x 2-1^{-1-}, 184 \pm 9$ cells $/ \mathrm{mm}^{2} ; p<0.05, t$ test), probably because of the reduced volume occupied by this structure in Nkx2-1 mutants. Altogether, these results strongly suggested that a large fraction of Npas $1^{+}$neurons in the GP derive from the LGE.

\section{Discussion}

Our results indicate that the assembly of forebrain nuclei is a much more complex process than previously anticipated. In contrast to the prevalent view that telencephalic nuclei primarily develop by radial migration of projection neurons from a single progenitor domain, our analysis indicates that assembly of a major forebrain nucleus, the GP, involves at least three major progenitor domains: the LGE, the MGE, and the POA (Fig. 9). Furthermore, because only one of these domains can be topologically radial to the developing GP (Misson et al., 1988) and this nucleus almost exclusively contains projection neurons (Kita, 2007), our results imply that tangential migration of projection neurons is required for the formation of forebrain nuclei. Thus, neuronal diversity within forebrain nuclei does not exclusively arise by the sequential generation of distinct classes of neurons 


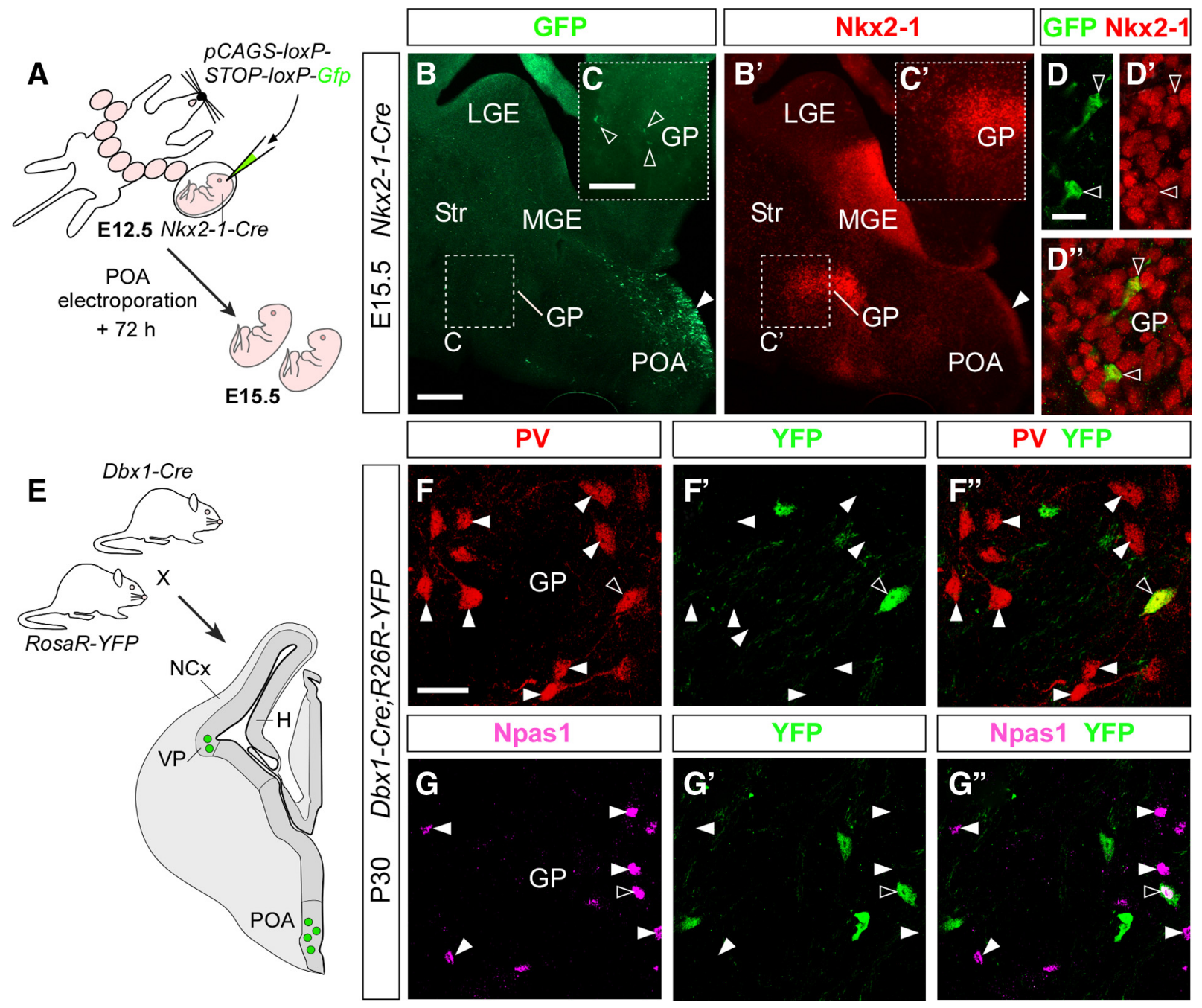

Figure 6. Origin of GP neurons in the POA. $\boldsymbol{A}$, Schematic of the experimental design. $\boldsymbol{B}-\boldsymbol{C}^{\prime}$, A representative case of the distribution of GFP-expressing $(\boldsymbol{B}, \boldsymbol{C})$ and Nkx2-1-expressing $\left(\boldsymbol{B}^{\prime}, \boldsymbol{C}^{\prime}\right)$ cells in a coronal section through the telencephalon of an E15.5 embryo in which the POA was electroporated at E12.5. The white arrowhead in $\boldsymbol{B}$ and $\boldsymbol{B}^{\prime}$ indicates the place of electroporation. $\boldsymbol{C}$ and $\boldsymbol{C}^{\prime}$ are high-magnification images of the GP from the boxed area shown in $\boldsymbol{B}$ and $\boldsymbol{B}^{\prime}$, respectively. $\boldsymbol{D}-\boldsymbol{D}^{\prime}$, Images of representative cells found in the GP after electroporation in the POA. $\boldsymbol{E}$, Schematic of the experimental design, indicating the progenitor domains labeled in Dbx1-Cre mice. Note that only a few progenitor cells within the ventral pallium (VP) and the POA express Dbx1. $F-G^{\prime \prime}$, Coronal sections through the telencephalon of P30 Dbx1-Cre;Rosa26R-YFP mice showing coexpression of PV $\left(\boldsymbol{F}, \boldsymbol{F}^{\prime \prime}\right)$ and Npas $1\left(\boldsymbol{G}, \boldsymbol{G}^{\prime \prime}\right)$ with $Y F P\left(\boldsymbol{F}^{\prime}, \boldsymbol{F}^{\prime \prime}, \boldsymbol{G}^{\prime}, \boldsymbol{G}^{\prime \prime}\right)$ in the GP. Open arrowheads point to examples of double-labeled cells, whereas filled arrowheads point to neurons that express only one of the markers. Scale bars: $\boldsymbol{B}, \boldsymbol{B}^{\prime}, 250 \mu \mathrm{m} ; \boldsymbol{C}^{\prime} \boldsymbol{C}^{\prime}, 100 \mu \mathrm{m} ; \boldsymbol{D}-\boldsymbol{D}^{\prime \prime}, 25 \mu \mathrm{m} ; \boldsymbol{F}-\boldsymbol{G}^{\prime \prime}, 50 \mu \mathrm{m}$. Str, Striatum; $H$, hippocampus.

from a common progenitor but also through the tangential recruitment of distinct classes of neurons from multiple distant progenitor pools.

\section{Multiple developmental origins underlie neuronal diversity} in the globus pallidus

It has typically been assumed that neurons in the GP derive from the MGE (Smart, 1976; Marchand and Lajoie, 1986; Sussel et al., 1999), although direct evidence for this hypothesis is scarce (Pakzaban et al., 1993; Wichterle et al., 2001). Our in utero electroporation and transplantation experiments, along with the analysis of Nkx2-1-Cre mice, revealed that many GP neurons arise from the MGE. These results are consistent with previous genetic analyses in which deletion of genes expressed in the MGE, such as $N k \times 2-1$, led to a prominent decrease in the number of GP neurons (Sussel et al., 1999). In contrast, previous in utero transplantation experiments did not identify the MGE as the main source of GP neurons in the mouse (Wichterle et al., 2001). The main difference between the experiments performed by Wichterle et al. (2001) and our experiments is the age of the donor cells (E13.5 and E12.5, respectively). Taking into account that most GP neurons are born between E10.5 and E12.5 (Fig. 2C) (Marchand and Lajoie, 1986), it is conceivable that this difference may account for the disparity in the results.

In addition to the MGE, our experiments revealed that neurons in the GP also derived from the POA and the LGE (Fig. 9). Fate-mapping analyses using Dbx1-Cre and Pax6-Cre mice provide direct evidence that some GP neurons are born outside the MGE, because neither one of these genes is expressed within this region (Flames et al., 2007). Analysis of Dbx1-Cre mice revealed that a small percentage of POA progenitors contribute to the complement of GP neurons. It is possible, however, that this analysis may underestimate the contribution of the POA to the GP, because $D b x 1$ is only expressed by some progenitor cells within this region (Flames et al., 2007). It should be noted, however, that neurons expressing $N k x 5-1$, which identifies another neuronal lineage emanating from the POA (Gelman et al., 2009), do not populate the GP. Similarly, Cre expression is mosaic in our 

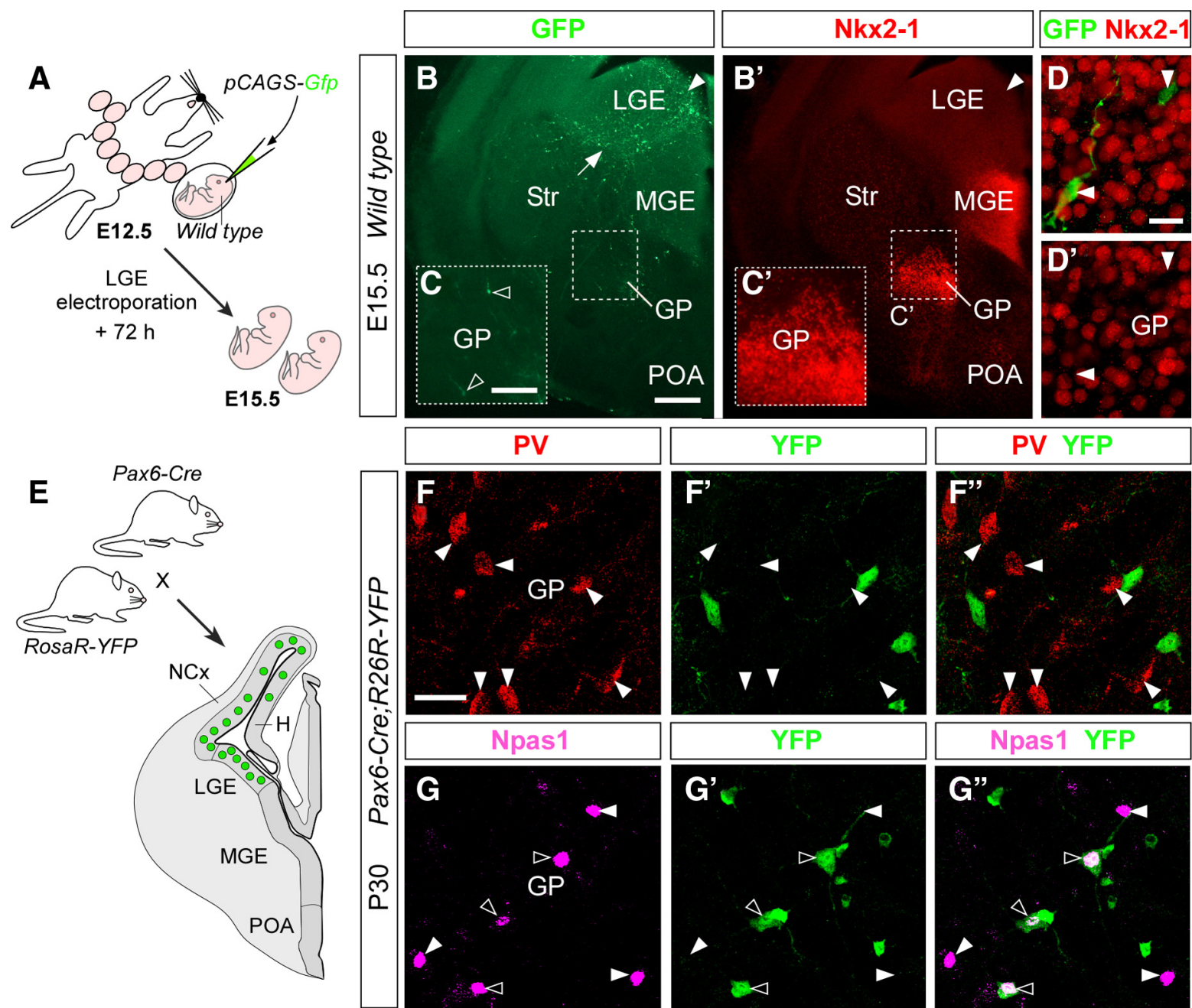

Figure 7. Origin of GP neurons in the LGE. $\boldsymbol{A}$, Schematic of the experimental design. $\boldsymbol{B}-\boldsymbol{C}^{\prime}, A$ representative case of the distribution of GFP-expressing $(\boldsymbol{B}, \boldsymbol{C})$ and Nkx2-1-expressing $\left(\boldsymbol{B}^{\prime}, \boldsymbol{C}^{\prime}\right)$ cells in a coronal section through the telencephalon of an E15.5 embryo in which the LGE was electroporated at E12.5. The white arrowhead in $\boldsymbol{B}$ and $\boldsymbol{B}^{\prime}$ indicates the place of electroporation. Note that most cells derived from the LGE seem to migrate radially toward the developing striatum (arrow), but a few appear to turn ventrally toward the GP. $C_{\text {and }} \boldsymbol{C}^{\prime}$ are high-magnification images of the GP from the boxed area shown in $\boldsymbol{B}$ and $\boldsymbol{B}^{\prime}$, respectively. $\boldsymbol{D}, \boldsymbol{D}^{\prime}$, Images of representative cells found in the GP after electroporation in the LGE. $\boldsymbol{E}$, Schematic of the experimental design, indicating the progenitor domains labeled in Pax6-Cre mice. $\boldsymbol{F}-\boldsymbol{G}^{\prime \prime}$, Coronal sections through the telencephalon of P30 Pax6-Cre;Rosa26R-YFP mice showing coexpression of PV $\left(\boldsymbol{F}, \boldsymbol{F}^{\prime \prime}\right)$ and Npas $1\left(\boldsymbol{G}, \boldsymbol{G}^{\prime \prime}\right)$ with $\operatorname{YFP}\left(\boldsymbol{F}^{\prime}, \boldsymbol{F}^{\prime \prime}, \boldsymbol{G}^{\prime}, \boldsymbol{G}^{\prime \prime}\right)$ in the GP. Open arrowheads point to examples of double-labeled cells, whereas filled arrowheads point to neurons that express only one of the markers. Scale bars: $\boldsymbol{B}, \boldsymbol{B}^{\prime}, 250 \mu \mathrm{m}$; $C_{,} \boldsymbol{C}^{\prime}, 100 \mu \mathrm{m} ; \boldsymbol{D}^{\prime}, \boldsymbol{D}^{\prime}, 25 \mu \mathrm{m} ; \boldsymbol{F}-\boldsymbol{G}^{\prime \prime}, 50 \mu \mathrm{m}$. Str, Striatum; NCX, neocortex.

Pax6-Cre mice, and therefore we could only trace a fraction of the derivatives of the LGE. Because progenitor cells throughout the pallium also express Pax6, it is conceivable that $\mathrm{Npas}^{+}$neurons may also derive from this region. Indeed, a recent study has suggested that pallial progenitors derived from an Emxl lineage may give rise to inhibitory cells in the striatum and amygdala (Cocas et al., 2009). Nevertheless, pallial cells do not seem to generate many GABAergic cells (Chapouton et al., 1999; Stoykova et al., 2000; Toresson et al., 2000), and a recent report has shown that EmxI-Cre mice also induce recombination in the subpallium (Waclaw et al., 2009). Another possible origin for GP neurons derived from the Pax6-Cre lineage is the preoptic-hypothalamic area $(\mathrm{POH})$, a territory adjacent to the POA (supplemental Fig. S2, available at www.jneurosci.org as supplemental material). In summary, both the POA and the LGE seem to give rise to neurons that populate the adult GP, although other sources, such as the pallium and $\mathrm{POH}$, may also contribute to the neuronal diversity found in this nucleus.

The analysis of Nkx2-1 embryos provided additional support to the hypothesis that many GP neurons derived from the LGE.
Previous studies have shown that loss of Nkx2-1 leads to a respecification of MGE progenitor cells in a temporally regulated manner, which results in the ectopic production of striatal projection neurons and some classes of cortical interneurons (Sussel et al., 1999; Butt et al., 2008). Because these neurons are thought to originate from different rostrocaudal levels of the LGE, these studies demonstrated that the LGE expands at the expense of MGE progenitors in the absence of Nkx2-1 function. The finding that the population of Npas1-expressing GP neurons is preserved in Nkx2-1 mutants therefore strongly suggests that many of these neurons derive from the LGE. The precise origin of Npas1expressing GP neurons within the LGE remains to be determined, although previous in utero transplantation experiments suggest that these neurons may originate from the caudal aspect of the LGE, also known as the caudal ganglionic eminence (CGE) (Nery et al., 2002). This region of the subpallium also expresses Pax6 and has been shown previously to be the origin of many tangentially migrating GABAergic neurons (Nery et al., 2002; Butt et al., 2008). Thus, it is possible that $\mathrm{Npas}^{+}{ }^{+}$neurons in the GP primarily originate from the CGE. Alternatively, these neu- 
rons may derive from the entire rostrocaudal extent of the subpallial Pax6 territory (i.e., LGE + CGE).

The discovery of multiple developmental origins for GP neurons suggests that neuronal diversity within this nucleus is relatively high (Fig. 9). Indeed, several classes of GABAergic projection neurons have been described based on various morphological and physiological criteria (Staines and Fibiger, 1984; Kita, 1994, 2007; Kita and Kitai, 1994; Bevan et al., 1998; Kita and Kita, 2001). For example, GP neurons project to other structures in the basal ganglia circuitry, such as the endopenduncular nucleus, the subthalamic nucleus, and the substantia nigra, but not all of them have the same specific synaptic target. In addition, approximately one-third of GP neurons also project to the striatum, in which they may contact either striatal projection neurons or interneurons (Bevan et al., 1998; Kita, 2007). GP neurons projecting to the striatum are typically immunonegative for PV, whereas nonstriatal projection GP neurons express PV (Kita and Kita, 2001). Thus, neuronal diversity of GP neurons, as revealed by their heterogeneous projection patterns and molecular features, seems to reflect the variety of progenitor pools involved in the generation of this structure.

Possible mechanisms controlling the migration of globus pallidus neurons There are no reports on the possible guidance mechanisms used by GP neurons to assemble in the basal telencephalon. The structure of the radial glia in the developing telencephalon, as revealed by RC2 staining (Misson et al., 1988), strongly

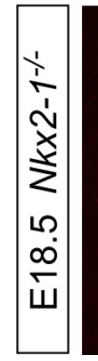

suggests that only GP neurons derived from the MGE may use radial glia as their principal mode of migration. In contrast, LGEand POA-derived GP neurons must necessarily reach their final position after migrating at least part of their trajectory following a tangential route.

The early neurogenesis of PV-expressing GP neurons (Fig. 2C) (Marchand and Lajoie, 1986) indicates that this population of cells may establish the foundation of this nucleus, with the remaining populations of GP neurons arriving afterward. In this model, cells derived from the MGE would first colonize the re-
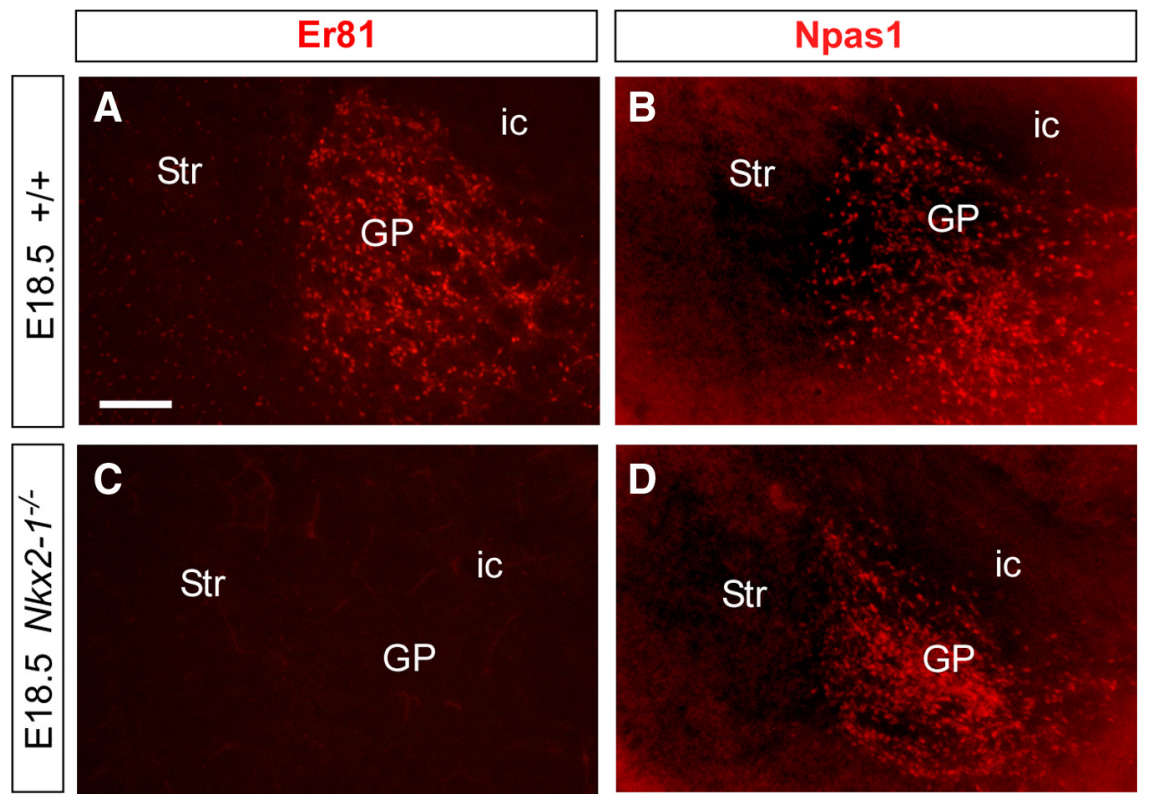

Figure 8. Npas1-expressing cells are present in the globus pallidus of Nkx2-1 mutants. $A-D$, Coronal sections through the telencephalon of E18.5 wild-type $(\boldsymbol{A}, \boldsymbol{B})$ and Nkx2-1 mutant $(\boldsymbol{C}, \boldsymbol{D})$ fetuses showing the distribution of Er81-expressing $(\boldsymbol{A}, \boldsymbol{C})$ and Npas1-expressing (B, D) cells in the GP. Scale bar, $250 \mu \mathrm{m}$. Str, Striatum; ic, internal capsule.

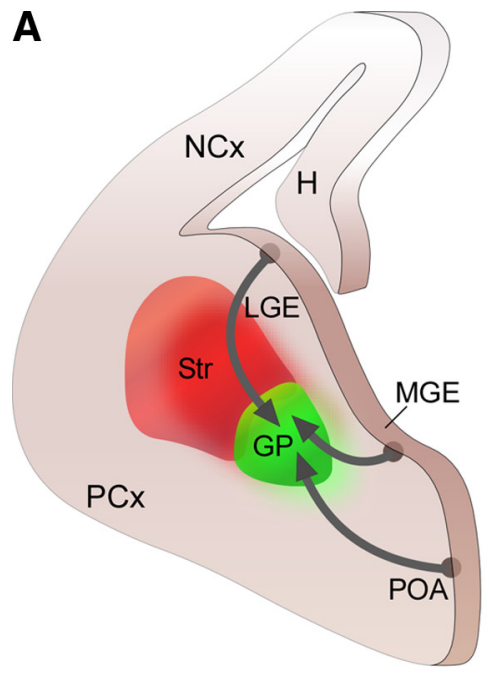

B

\begin{tabular}{|c|c|c|c|}
\hline Profile & Lineage & Origin & $\%$ GP \\
\hline Npas1 & Pax6 & LGE1 $^{1}$ & 25.0 \\
\hline Npas1 & Nkx2-1 & MGE & 24.0 \\
\hline Npas1 & Nkx2-1/Dbx1 & $\mathrm{POA}^{2}$ & 1.00 \\
\hline$P V+N k x 2-1+E r 81$ & Nkx2-1 & MGE & $46.5 \bigcirc$ \\
\hline \multirow[t]{2}{*}{$P V+N k \times 2-1+E r 81$} & Nkx2-1/Dbx1 & $\mathrm{POA}^{2}$ & 3.50 \\
\hline & & & 100.0 \\
\hline
\end{tabular}

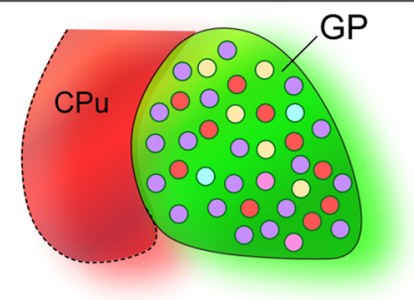

Figure 9. Neuronal diversity in the globus pallidus emerges from different and distant progenitor pools. $\boldsymbol{A}$, Schematic representation of a transversal hemisection through an E13.5 developing telencephalon, depicting the putative routes of migration of GP neurons from their origins to their final destination. $B$, Schematic representation of neuronal diversity in the GP, based on the molecular profile of its constituents and their differential origin. 1, The contribution of the Pax6-expressing territory (LGE proper and/or CGE) to the population of Npas $1{ }^{+}$neurons is inferred from the fate-mapping analysis of NkX2-1-Cre;Rosa26R-YFP mice, because expression of Cre in Pax6 -Cre mice is mosaic and does not label all LGE progenitors. In addition, it should be noted that the POH also expresses Pax6 (supplemental Fig. S2, available at www.jneurosci.org as supplemental material), and therefore some Npas $1^{+}$neurons might derive from this region. 2 , The contribution of the POA to the GP might be underestimated, because progenitors other than those expressing Dbx 1 may give rise to GP neurons. If this were the case, then the contribution of the MGE to the GP would be overestimated. H, Hippocampus; CPu, caudoputamen nucleus; PCx, piriform cortex; Str, striatum. 
gion in which the GP would eventually form, and then neurons derived from the LGE and POA would join this structure. This would suggest that GP pioneer neurons could provide guidance cues for the tangentially migrating component of the GP, similar to what has been proposed for striatal neurons (Marín et al., 2000). Alternatively, each population of GP neurons might be directed to independently assemble in the caudomedial aspect of the developing striatum. This would be consistent with the finding that LGE-derived GP neurons aggregate in the correct location in the absence of MGE- and POA-derived GP neurons, as observed in Nkx2-1 mutants. Thus, each population of neurons may rely on independent guidance mechanisms to assemble into the GP.

\section{Nuclear assembly in the developing telencephalon}

Our understanding of the formation of laminar structures in the telencephalon, such as the neocortex or the hippocampus, has massively expanded over the past 10 years (Gupta et al., 2002; Marín and Rubenstein, 2003; Ayala et al., 2007). In the cortex, projection neurons arise to their final destination through radial migration, which serves to maintain relatively stable topological relationships between the ventricular zone and the underlying mantle (Rakic, 1988, 2007). In contrast, interneurons reach the cortex through a long tangential migration (Corbin et al., 2001; Métin et al., 2006), which has led to the suggestion that this mechanism serves to increase neuronal diversity in the developing brain (Marín and Rubenstein, 2001). In the basal telencephalon, at least two nuclear structures seem to develop following the same principles. In the striatum, projection neurons appear to migrate radially from the LGE (Halliday and Cepko, 1992; Hamasaki et al., 2001), whereas interneurons reach their target from the MGE by tangential migration (Marín et al., 2000). Similarly, recent work has shown that the medial nucleus of the amygdala also forms by gathering radially migrating projection neurons from the LGE and tangentially migrating interneurons from the POA (Carney et al., 2006; Hirata et al., 2009).

Our study suggests that the assembly of forebrain nuclei might require a more complex set of events. Formation of the GP involves merging several different populations of cells that eventually will develop into distinct classes of projection neurons. This is relatively common to other forebrain nuclei, for which distinct classes of projection neurons have been described. In the striatum, for example, "matrix" and "striosome" projection neurons are generated at different times and have distinct connectivity patterns (van der Kooy and Fishell, 1987; Gerfen, 1992). However, what is remarkable about the GP is that different classes of projection neurons seem to derive from relatively distant progenitor pools, and many of them might reach their final destination through tangential migration. Thus, our results suggest that tangential migration in the forebrain is not limited to interneurons but also involves projection neurons. In addition, our experiments imply that the formation of topographical connections is not directly linked to the process of radial migration, because organized connectivity also emerges from brain structures with very elaborated patterns of nuclear assembly, such as the GP.

\section{References}

Ayala R, Shu T, Tsai LH (2007) Trekking across the brain: the journey of neuronal migration. Cell 128:29-43.

Bevan MD, Booth PA, Eaton SA, Bolam JP (1998) Selective innervation of neostriatal interneurons by a subclass of neuron in the globus pallidus of the rat. J Neurosci 18:9438-9452.

Bielle F, Griveau A, Narboux-Nême N, Vigneau S, Sigrist M, Arber S, Wassef
M, Pierani A (2005) Multiple origins of Cajal-Retzius cells at the borders of the developing pallium. Nat Neurosci 8:1002-1012.

Borrell V, Yoshimura Y, Callaway EM (2005) Targeted gene delivery to telencephalic inhibitory neurons by directional in utero electroporation. J Neurosci Methods 143:151-158.

Butt SJ, Sousa VH, Fuccillo MV, Hjerling-Leffler J, Miyoshi G, Kimura S, Fishell G (2008) The requirement of Nkx2-1 in the temporal specification of cortical interneuron subtypes. Neuron 59:722-732.

Carney RS, Alfonso TB, Cohen D, Dai H, Nery S, Stoica B, Slotkin J, Bregman BS, Fishell G, Corbin JG (2006) Cell migration along the lateral cortical stream to the developing basal telencephalic limbic system. J Neurosci 26:11562-11574.

Chapouton P, Gärtner A, Götz M (1999) The role of Pax6 in restricting cell migration between developing cortex and basal ganglia. Development 126:5569-5579.

Cobos I, Long JE, Thwin MT, Rubenstein JLR (2006) Cellular patterns of transcription factor expression in developing cortical interneurons. Cereb Cortex 16 [Suppl 1]:i82-i88.

Cocas LA, Miyoshi G, Carney RS, Sousa VH, Hirata T, Jones KR, Fishell G, Huntsman MM, Corbin JG (2009) Emx1-lineage progenitors differentially contribute to neural diversity in the striatum and amygdala. J Neurosci 29:15933-15946.

Cooper AJ, Stanford IM (2000) Electrophysiological and morphological characteristics of three subtypes of rat globus pallidus neurone in vitro. J Physiol 527:291-304.

Corbin JG, Nery S, Fishell G (2001) Telencephalic cells take a tangent: nonradial migration in the mammalian forebrain. Nat Neurosci [Suppl] 4:1177-1182.

Deacon TW, Pakzaban P, Isacson O (1994) The lateral ganglionic eminence is the origin of cells committed to striatal phenotypes: neural transplantation and developmental evidence. Brain Res 668:211-219.

Flames N, Pla R, Gelman DM, Rubenstein JL, Puelles L, Marín O (2007) Delineation of multiple subpallial progenitor domains by the combinatorial expression of transcriptional codes. J Neurosci 27:9682-9695.

Gelman DM, Martini FJ, Nóbrega-Pereira S, Pierani A, Kessaris N, Marín O (2009) The embryonic preoptic area is a novel source of cortical GABAergic interneurons. J Neurosci 29:9380-9389.

Gerfen CR (1992) The neostriatal mosaic: multiple levels of compartmental organization. Trends Neurosci 15:133-139.

Gupta A, Tsai LH, Wynshaw-Boris A (2002) Life is a journey: a genetic look at neocortical development. Nat Rev Genet 3:342-355.

Hadjantonakis AK, Macmaster S, Nagy A (2002) Embryonic stem cells and mice expressing different GFP variants for multiple non-invasive reporter usage within a single animal. BMC Biotechnol 2:11.

Halliday AL, Cepko CL (1992) Generation and migration of cells in the developing striatum. Neuron 9:15-26.

Hamasaki T, Goto S, Nishikawa S, Ushio Y (2001) A role of netrin-1 in the formation of the subcortical structure striatum: repulsive action on the migration of late-born striatal neurons. J Neurosci 21:4272-4280.

Hamasaki T, Goto S, Nishikawa S, Ushio Y (2003) Neuronal cell migration for the developmental formation of the mammalian striatum. Dev Brain Res 41:1-12.

Hirata T, Li P, Lanuza GM, Cocas LA, Huntsman MM, Corbin JG (2009) Identification of distinct telencephalic progenitor pools for neuronal diversity in the amygdala. Nat Neurosci 12:141-149.

Kita H (1994) Parvalbumin-immunopositive neurons in rat globus pallidus: a light and electron microscopic study. Brain Res 657:31-41.

Kita H (2007) Globus pallidus external segment. Prog Brain Res 160:111-133.

Kita H, Kita T (2001) Number, origins, and chemical types of rat pallidostriatal projection neurons. J Comp Neurol 437:438-448.

Kita H, Kitai ST (1994) The morphology of globus pallidus projection neurons in the rat: an intracellular staining study. Brain Res 636:308-319.

Leone DP, Srinivasan K, Chen B, Alcamo E, McConnell SK (2008) The determination of projection neuron identity in the developing cerebral cortex. Curr Opin Neurobiol 18:28-35.

Lin JH, Saito T, Anderson DJ, Lance-Jones C, Jessell TM, Arber S (1998) Functionally related motor neuron pool and muscle sensory afferent subtypes defined by coordinate ETS gene expression. Cell 95:393-407.

Marchand R, Lajoie L (1986) Histogenesis of the striopallidal system in the rat. Neurogenesis of its neurons. Neuroscience 17:573-590. 
Marín O, Rubenstein JL (2001) A long, remarkable journey: tangential migration in the telencephalon. Nat Rev Neurosci 2:780-790.

Marín O, Rubenstein JL (2003) Cell migration in the forebrain. Annu Rev Neurosci 26:441-483.

Marín O, Anderson SA, Rubenstein JL (2000) Origin and molecular specification of striatal interneurons. J Neurosci 20:6063-6076.

Métin C, Baudoin JP, Rakić S, Parnavelas JG (2006) Cell and molecular mechanisms involved in the migration of cortical interneurons. Eur J Neurosci 23:894-900.

Misson JP, Edwards MA, Yamamoto M, Caviness VS Jr (1988) Identification of radial glial cells within the developing murine central nervous system: studies based upon a new immunohistochemical marker. Dev Brain Res 44:95-108.

Mitrofanis J (1992) Patterns of antigenic expression in the thalamic reticular nucleus of developing rats. J Comp Neurol 320:161-181.

Molyneaux BJ, Arlotta P, Menezes JR, Macklis JD (2007) Neuronal subtype specification in the cerebral cortex. Nat Rev Neurosci 8:427-437.

Nadarajah B, Parnavelas JG (2002) Modes of neuronal migration in the developing cerebral cortex. Nat Rev Neurosci 3:423-432.

Nambu A, Llinás R (1994) Electrophysiology of globus pallidus neurons in vitro. J Neurophysiol 72:1127-1139.

Nambu A, Llinás R (1997) Morphology of globus pallidus neurons: its correlation with electrophysiology in guinea pig brain slices. J Comp Neurol 377:85-94.

Nery S, Fishell G, Corbin JG (2002) The caudal ganglionic eminence is a source of distinct cortical and subcortical cell populations. Nat Neurosci 5:1279-1287.

Nóbrega-Pereira S, Kessaris N, Du T, Kimura S, Anderson SA, Marín O (2008) Postmitotic Nkx2-1 controls the migration of telencephalic interneurons by direct repression of guidance receptors. Neuron 59:733-745.

Noctor SC, Martínez-Cerdeño V, Ivic L, Kriegstein AR (2004) Cortical neurons arise in symmetric and asymmetric division zones and migrate through specific phases. Nat Neurosci 7:136-144.

Olsson M, Campbell K, Wictorin K, Björklund A (1995) Projection neurons in fetal striatal transplants are predominantly derived from the lateral ganglionic eminence. Neuroscience 69:1169-1182.

Olsson M, Björklund A, Campbell K (1998) Early specification of striatal projection neurons and interneuronal subtypes in the lateral and medial ganglionic eminence. Neuroscience 84:867-876.

Pakzaban P, Deacon TW, Burns LH, Isacson O (1993) Increased proportion of acetylcholinesterase-rich zones and improved morphological integration in host striatum of fetal grafts derived from the lateral but not the medial ganglionic eminence. Exp Brain Res 97:13-22.

Pla R, Borrell V, Flames N, Marín O (2006) Layer acquisition by cortical GABAergic interneurons is independent of Reelin signaling. J Neurosci 26:6924-6934.
Rakic P (1972) Mode of cell migration to the superficial layers of fetal monkey neocortex. J Comp Neurol 145:61-83.

Rakic P (1988) Specification of cerebral cortical areas. Science 241:170-176.

Rakic P (2007) The radial edifice of cortical architecture: from neuronal silhouettes to genetic engineering. Brain Res Rev 55:204-219.

Rakic P, Stensas LJ, Sayre E, Sidman RL (1974) Computer-aided threedimensional reconstruction and quantitative analysis of cells from serial electron microscopic montages of foetal monkey brain. Nature 250:31-34.

Smart IH (1976) A pilot study of cell production by the ganglionic eminences of the developing mouse brain. J Anat 121:71-84.

Srinivas S, Watanabe T, Lin CS, William CM, Tanabe Y, Jessell TM, Costantini F (2001) Cre reporter strains produced by targeted insertion of EYFP and ECFP into the ROSA26 locus. BMC Dev Biol 1:4.

Staines WA, Fibiger HC (1984) Collateral projections of neurons of the rat globus pallidus to the striatum and substantia nigra. Exp Brain Res $56: 217-220$.

Stenman J, Toresson H, Campbell KJ (2003) Identification of two distinct progenitor populations in the lateral ganglionic eminence: implications for striatal and olfactory bulb neurogenesis. J Neurosci 23:167-174.

Stoykova A, Treichel D, Hallonet M, Gruss P (2000) Pax6 modulates the dorsoventral patterning of the mammalian telencephalon. J Neurosci 20:8042-8050.

Sussel L, Marín O, Kimura S, Rubenstein JL (1999) Loss of Nkx2.1 homeobox gene function results in a ventral to dorsal molecular respecification within the basal telencephalon: evidence for a transformation of the pallidum into the striatum. Development 126:3359-3370.

Toresson H, Potter SS, Campbell KJ (2000) Genetic control of dorsalventral identity in the telencephalon: opposing roles for Pax6 and Gsh2. Development 127:4361-4371.

van der Kooy D, Fishell G (1987) Neuronal birthdate underlies the development of striatal compartments. Brain Res 401:155-161.

Waclaw RR, Wang B, Pei Z, Ehrman LA, Campbell K (2009) Distinct temporal requirements for the homeobox gene Gsx2 in specifying striatal and olfactory bulb neuronal fates. Neuron 63:451-465.

Wichterle H, Turnbull DH, Nery S, Fishell G, Alvarez-Buylla A (2001) In utero fate mapping reveals distinct migratory pathways and fates of neurons born in the mammalian basal forebrain. Development 128:3759-3771

Wonders CP, Anderson SA (2006) The origin and specification of cortical interneurons. Nat Rev Neurosci 7:687-696.

Xu Q, Tam M, Anderson SA (2008) Fate mapping Nkx2.1-lineage cells in the mouse telencephalon. J Comp Neurol 506:16-29.

Zhou YD, Barnard M, Tian H, Li X, Ring HZ, Francke U, Shelton J, Richardson J, Russell DW, McKnight SL (1997) Molecular characterization of two mammalian bHLH-PAS domain proteins selectively expressed in the central nervous system. Proc Natl Acad Sci U S A 94:713-718. 